\title{
REPARAÇÃO DA DÍVIDA SOCIAL DA EXCLUSÃO: UMA FUNÇÃO DA EDUCAÇÃO DE JOVENS E ADULTOS NO BRASIL?
}

\author{
CHILANTE, Edinéia Fátima Navarro (FAFIPA) \\ bchilante@hotmail.com \\ NOMA, Amélia Kimiko (UEM) \\ aknoma@uem.br
}

\section{RESUMO:}

No presente texto, analisa-se a função de reparação da dívida social atribuída à Educação de Jovens e Adultos (EJA) pelo Parecer CNE/CEB 11/2000 e pela Resolução CNE/CEB 1/2000. O objetivo é discutir a idéia de inclusão expressa nos documentos legais pertinentes a essa modalidade da educação básica destinada ao atendimento de alunos que não tiveram, na idade própria, acesso ou continuidade de estudo. Para tal, a abordagem do objeto em estudo é articulada com as condições históricas específicas em que ele foi constituído e instituído, porque a análise pretendida não pode ser consubstanciada em espaço social vazio.

Palavras-chave: Educação pública. Políticas educacionais. Função reparadora. Educação de Jovens e Adultos.

\section{REPAIR OF SOCIAL EXCLUSION OF LIABILITY: THE ROLE OF THE EDUCATION OF YOUNG PEOPLE AND ADULTS IN BRAZIL?}

\begin{abstract}
:
The present text analyses the function of the social debt settlement conferred to The Young People and Adult Education (EJA) by the Parecer CNE/CEB 11/2000 and Resolução $\mathrm{CNE} / \mathrm{CEB} 1 / 2000$ documents. The purpose is to discuss the inclusion idea expressed on these legal documents which belong to this basic education modality designed to the assistance of student who did not have, at the appropriate age, access or continuity of their studies. For this, the study object approach is articulated to the specific historical conditions in which it was constituted and implemented because the intended analysis can not be consolidated in an empty social space.

Key-words: Public education, Educational policies, settlement function, Young People and Adult Education.

\section{Introdução}

O Parecer CNE/CEB 11/2000 e a Resolução CNE/CEB 1/2000, que instituem as Diretrizes Curriculares Nacionais para a Educação de Jovens e Adultos (EJA), atribuem a essa modalidade da educação básica a função de reparação da dívida social resultante da história excludente do nosso país. Esses documentos legais, ao adotarem a idéia da inclusão educacional, fazem a defesa do atendimento de alunos que não tiveram, na idade própria, acesso ou continuidade de estudo. Mais do que um direito, a EJA é considerada a chave para o século XXI, por ser resultante do exercício da cidadania e condição para a participação plena na sociedade, incluindo aí a qualificação e a requalificação profissional.
\end{abstract}


Nos documentos orientadores das políticas públicas de EJA produzidos no Brasil ao final do século XX, argumenta-se que a mesma pode auxiliar na eliminação das discriminações e na busca de uma sociedade mais justa e menos desigual, a qual resultaria da inclusão do conjunto de brasileiros vítimas da nossa história excludente. A EJA é tratada como uma dívida social a ser reparada, devendo, portanto, assumir a tarefa de estender a todos o acesso e o domínio da escrita e da leitura como bens sociais, seja na escola, seja fora dela.

Para a consecução do aqui proposto, abordamos o objeto em foco buscando estabelecer a relação do mesmo com as condições históricas específicas em que ele foi constituído e instituído. Entendemos que a análise pretendida não pode ser consubstanciada em espaço social vazio, nem realizada restringindo-se apenas a aspectos da legislação educacional brasileira e ao campo estritamente educacional.

$\mathrm{Na}$ primeira parte deste texto, após expor a configuração da EJA na Lei de Diretrizes e Bases da Educação anterior (Lei 5.692/71) e no Parecer CNE 699/72, apresentamos as bases legais atuais da Educação de Jovens e Adultos: a Constituição Federal de 1988; a Lei de Diretrizes e Bases da Educação Nacional de 1996; o Parecer CNE/CEB 11/2000 e a Resolução CNE/CEB 1/2000. Na segunda parte, fazemos uma crítica à promessa de reparação, apresentada como uma das funções da EJA nos documentos legais analisados.

\section{A legislação nacional de EJA}

A Lei de Diretrizes e Bases da Educação Nacional (LDB) 5.692/71, ao estabelecer as diretrizes e bases do ensino de $1^{\circ}$ e $2^{\circ}$ graus, não incluiu no Sistema de Ensino aqueles que não estudaram em idade considerada apropriada (dos 7 aos 14 anos). Criou, no entanto, um sistema de atendimento paralelo ao sistema de Ensino Regular. O Ensino Supletivo, nesse período, configurou-se em um subsistema do Ensino Regular e abrangia o processo de alfabetização, a aprendizagem, a qualificação, algumas disciplinas e também a atualização. Os cursos podiam ser a distância (correio), com a certificação via exames, realizados em estabelecimentos oficiais ou não, sob a responsabilidade dos Conselhos Estaduais de Educação (BRASIL, 2000). O Parecer 699/72 do Conselho Nacional de Educação, elaborado por Valnir Chagas, regulamentava o então ensino supletivo e lhe atribuía quatro funções: suplência, substituição compensatória do ensino regular - via cursos ou exames -, suprimento, complementação do inacabado por meio de aperfeiçoamento e atualização; aprendizagem e qualificação, que só teriam certificados de conclusão nas etapas de $5^{\mathrm{a}}$ a $8^{\mathrm{a}}$ séries ou $2^{\circ}$ grau quando incluíssem disciplinas, áreas de estudo e atividades que os tornassem equivalentes ao ensino regular (BRASIL, 2000). Das referidas funções, o que prevaleceu durante toda a existência do Ensino Supletivo foi a suplência ofertada pelos entes federativos com o objetivo de alfabetização, na maioria das vezes, realizada por meio de campanhas. Além disso, a EJA, nas suas etapas fundamental e média, como forma de correção de fluxo do sistema escolar.

A Constituição Federal, aprovada em 1988, ampliou o atendimento aos jovens e aos adultos ao considerar como dever do Estado a oferta do ensino fundamental obrigatório e gratuito, inclusive para aqueles que não tiveram a ele acesso na idade apropriada (Art. 208). Todavia a Emenda Constitucional 14/96 deu nova redação ao referido Artigo suprimindo a obrigatoriedade do Estado no atendimento da população jovem e adulta, mantendo somente a sua gratuidade. Sob este princípio foi criado o Fundo de Manutenção e Desenvolvimento do Magistério (Fundef), a Lei 9.424, de 24 de dezembro de 1996. Essa lei, que operacionalizou a distribuição de responsabilidades e recursos entre os estados e os 
seus municípios, deixou a EJA fora dos cálculos para o repasse de verbas em decorrência do veto do presidente Fernando Henrique Cardoso ao inciso II do parágrafo $1^{\circ}$ do art. $2^{\circ}$. Neste ponto, salientamos que o oferecimento de educação continuada aos jovens e aos adultos tem sido limitado pela escassez de recursos financeiros disponíveis para essa modalidade da educação básica.

A Lei de Diretrizes e Bases da Educação Nacional (LDB) de 1996 prevê a organização do sistema educacional brasileiro em dois níveis: a educação básica - formada pela educação infantil, ensino fundamental e ensino médio - e o ensino superior. Apresenta as seguintes modalidades de educação: educação de jovens e de adultos; educação profissional; educação especial; educação indígena e educação a distância. A denominação "Educação de Jovens e Adultos" substitui o que na Lei $n^{\circ}$. 5.692/71 era chamado de "Ensino Supletivo".

Na LDB-1996, a Educação de Jovens e Adultos é objeto dos artigos 37 e 38 nos quais é explicitado que compete aos sistemas de ensino assegurar gratuitamente oportunidades educacionais, de maneira apropriada para essa parcela da população, por meio dos cursos e de exames supletivos. Estabelece, também, que o poder público deve viabilizar o acesso e a permanência dos alunos jovens e adultos na escola.

A partir de meados dos anos 1990, as ações do Governo Federal direcionadas para a EJA caracterizaram-se por intervenções focalizadas e de caráter compensatório, na forma de programas, dentre as quais se destacam: o Programa Alfabetização Solidária (PAS); o Programa Nacional de Educação na Reforma Agrária (Pronera) ${ }^{1}$; o Plano Nacional de Qualificação do Trabalhador (Planfor) ${ }^{2}$; o Programa Recomeço e, atualmente, o Programa Brasil Alfabetizado (DI PIERRO; GRACIANO, 2003, p. 17). Esses programas contam, ou contaram, com a participação de empresas, sindicatos, federações e universidades, caracterizando uma intensa mobilização da sociedade civil na oferta de EJA sob regime de parceria.

O Conselho Nacional de Educação (CNE), por intermédio da Câmara de Educação Básica (CEB), expediu a Resolução CNE/CEB no. 1, de 05 de julho de 2000, a qual, ao tomar como referência o Parecer CNE/CEB 11/2000 - homologado pelo Ministro da Educação em 07 de julho de 2000 -, instituiu as Diretrizes Curriculares Nacionais para a EJA. A Resolução CNE/CEB 1/2000, em seus 25 artigos, normatiza a educação de pessoas jovens e adultas em todas as suas modalidades, definindo diretrizes nacionais que devem, obrigatoriamente, ser observadas na oferta da EJA, nas etapas fundamental e média, em instituições que integrem a organização da educação nacional, considerando o caráter próprio desta modalidade de educação.

Destaca-se que a configuração assumida pela EJA, a partir dos anos 1990, está inserida no contexto de reorganização do capital, sob novos parâmetros de produção e acumulação resultantes da resposta do capitalismo mundial à crise geral, que se tornou mais evidente a partir da década de 1970. É preciso lembrar que a permanência da produção capitalista não depende apenas da produção e da reprodução de mercadorias e de mais-valia, é imprescindível a produção e a reprodução das relações sociais. O que significa afirmar que, para rearticular-se e sair da crise, a "[...] reprodução capitalista só é viável se ela reproduzir as relações sociais que põem frente a frente capitalistas e proletários" (NETTO; BRAZ 2006, p. 136). Destarte, em âmbito mundial, “[...] a estratégia do grande capital visa romper com todas as barreiras sociopolíticas, e não somente com aquelas que dizem respeito às suas relações com o trabalho" com a pretensão de aniquilar qualquer trava extra-econômica aos seus movimentos (NETTO; BRAZ, 2006, p. 226).

Com o propósito de legitimar essa estratégia, "[...] o grande capital fomentou e patrocinou a divulgação maciça do conjunto ideológico que se difundiu sob a designação 
de neoliberalismo [...]" (NETTO; BRAZ, 2006, p.226). Neoliberalismo é a ideologia do capitalismo na fase em que há a predominância de um regime de acumulação predominantemente financeiro (MORAES, 2000).

No Brasil, nos anos 1990, o neoliberalismo forneceu a sustentação necessária às práticas político-econômicas regidas por influências de países hegemônicos e por seus agentes internacionais, com a participação e o consentimento de atores nacionais. As reformas educacionais que se seguiram aos anos 1990, em especial as que configuraram a EJA, foram parte do ajuste estrutural que desencadeou as reformas do Estado nos planos político-institucional, econômico e administrativo. Neste contexto, à educação, em especial à educação básica, é atribuído um papel decisivo no crescimento econômico, na redução da pobreza e na superação das desigualdades entre os países e entre os indivíduos de uma mesma nação.

\section{A educação de jovens e adultos reparadora}

O Parecer CNE/CEB 11/2000, relatado por Carlos Roberto Jamil Cury, trata das Diretrizes Nacionais Curriculares para a Educação de Jovens e Adultos. O texto completo consta de duas partes: I - Relatório e voto do relator; II - a Decisão da Câmara. Na primeira parte, o relator, ao estabelecer os conceitos e funções da EJA, aponta para a existência, no Brasil, de uma dualidade, e caracteriza a separação entre os alfabetizados/analfabetos, letrados/iletrados como se constituíssem um "[...] novo divisor entre cidadãos" (BRASIL, 2000, p. 28).

O Parecer se dirige aos sistemas de ensino e aos respectivos estabelecimentos que se ocupam da EJA nas formas presencial e semipresencial, de cursos que tenham como objeto a certificação de conclusão de etapas da educação básica. Para esses estabelecimentos, as Diretrizes Curriculares são obrigatórias. As mesmas Diretrizes, diferentemente, são somente referenciais pedagógicos às iniciativas da sociedade civil que desenvolverem programas de educação que não visem certificação oficial de conclusão de estudos das etapas da educação básica (BRASIL, 2000, p. 28).

A EJA, segundo o Parecer 11/2000, tem como funções a reparação, a equalização e a qualificação. A primeira, a função reparadora, é justificada, no Parecer CNE/CEB 11/2000, pelo alto número de analfabetos existente no Brasil. Considera o documento em questão que a focalização das políticas públicas no ensino fundamental teve como resultado a ampliação do número de crianças na escola. Aponta que, nos últimos anos, foram grandes os avanços quanto à universalização do Ensino Fundamental, em obediência ao princípio da obrigatoriedade escolar. Argumenta, contudo, que condições sociais adversas e as sequielas de um passado ainda mais perverso, associadas a inadequados fatores administrativos e de planejamento e dimensões qualitativas internas à escolarização têm condicionado o insucesso de muitos alunos (BRASIL, 2000, p. 30). O Parecer reconhece os avanços das políticas públicas em garantir a universalização da Educação e, ao mesmo tempo, considera que condições histórico-sociais comprometem o empenho dos poderes públicos em assegurar uma educação básica para todos.

Em decorrência dos condicionantes do insucesso escolar de muitas crianças, tem-se que: 1) a média nacional de permanência na escola, no Brasil, fica entre quatro e seis anos, quando deveria ser de oito; 2) o tempo médio de conclusão do ensino fundamental se converte em onze anos, quando os alunos já deveriam estar cursando o ensino médio. Após diagnosticar essa distorção idade/série, o Parecer enfatiza a problemática da repetência, da reprovação e da evasão, e conclui que "o quadro sócio- educacional seletivo continua a 
reproduzir excluídos dos ensinos fundamental e médio, mantendo adolescentes, jovens e adultos sem escolaridade obrigatória completa" (BRASIL, 2000, p. 30).

Para amenizar os efeitos da exclusão educacional, no Parecer, são apontadas algumas ações que propiciariam atendimento mais aberto a adolescentes e jovens: as classes de aceleração e os programas de renda negativa, como o Bolsa-família. As primeiras objetivariam a correção da distorção idade/série escolar e os programas permitiriam a permanência da criança na escola, com a diminuição do trabalho infantil. A distinção entre as classes de aceleração e a EJA é que as primeiras "[...] são um meio didático-pedagógico e pretendem, com metodologia própria, dentro do ensino de 7 a 14 anos, sincronizar o ingresso de estudantes com distorção idade/ano escolar". A EJA “[...] é uma categoria organizacional constante da estrutura da educação nacional, com finalidades e funções específicas" (BRASIL, 2000, p. 31).

Mesmo considerando os esforços de correção idade/série escolar e os incentivos à permanência das crianças na escola, as estatísticas educacionais no Brasil apontam um grande número de analfabetos, um total de 14,7\%, para a população de 15 anos de idade ou mais. Para esses, o Parecer aponta a EJA como uma forma de acabar com o analfabetismo, considerado uma dívida social, visto que a população analfabeta constitui-se de pessoas que não tiveram acesso nem domínio da leitura e da escrita como bem social, sendo a mão-deobra empregada na constituição de riquezas do nosso país. Ser analfabeto - argumenta significa a "[...] perda de um instrumento imprescindível para uma presença significativa na convivência social contemporânea" (BRASIL, 2000, p. 32).

Ressalta o Parecer que a ausência de escolarização não pode justificar uma visão preconceituosa do analfabeto ou iletrado, já que, na sociedade atual, ser analfabeto não significa estar totalmente de fora das práticas sociais de leitura e escrita. $\mathrm{O}$ argumento utilizado é que:

[...] um adulto pode ser analfabeto, porque marginalizado social e economicamente, mas, se vive em um meio em que a leitura e a escrita têm presença forte, se interessa em ouvir a leitura de jornais feita por um alfabetizado, se recebe cartas que outros lêem para ele, se dita cartas para que um alfabetizado as escreva..., se pede a alguém que lhe leia avisos ou indicações afixados em algum lugar, esse analfabeto é, de certa forma, letrado, porque faz uso da escrita, envolve-se em práticas sociais de leitura e de escrita (SOARES, 1998, p. 24, apud BRASIL, 2000, p. 33).

Mesmo considerando a participação do iletrado na sociedade letrada, o Parecer argumenta que o fato de o analfabeto não estar em iguais condições no interior de uma sociedade predominantemente grafocêntrica, na qual a escrita é privilegiada, é uma problemática a ser enfrentada. Sendo assim, o não-acesso a patamares mais elevados de letramento torna-se danoso para a conquista de uma cidadania plena (BRASIL, 2000).

Nesse ponto, o Parecer reconhece que as raízes do analfabetismo no Brasil são de ordem histórico-social, e aponta que a elite dirigente do país sempre atribuiu um papel subalterno à "[...] educação escolar de negros escravizados, índios reduzidos, caboclos migrantes e trabalhadores braçais" (BRASIL, 2000, p. 33). Hoje, os descendentes desses grupos sofrem as consequiências dessa realidade histórica. Cumpre, então, à EJA fazer a reparação dessa realidade, recuperando o princípio da igualdade para todos. A idéia é que a EJA garantiria "[...] uma reparação corretiva, ainda que tardia, de estruturas arcaicas, possibilitando aos indivíduos novas inserções no mundo do trabalho, na vida social, nos espaços da estética e na abertura dos canais de participação" (BRASIL, 2000, p. 38). 
A EJA reparadora significa, pela entrada no circuito dos direitos civis, a restauração do direito a uma escola de qualidade e o "[...] reconhecimento da igualdade ontológica de todo e qualquer ser humano" (BRASIL, 2000, p. 34). A justificativa para essa idéia está ancorada na Declaração de Hamburgo (BRASIL, 1998, p. 92), na qual consta que, entendida a alfabetização como o conhecimento básico que é necessário a todos num mundo em transformação, é concebida como um direito humano fundamental. "Em toda a sociedade, a alfabetização é uma habilidade primordial em si mesma e um dos pilares para o desenvolvimento de outras habilidades". O desafio que se apresenta é oferecer esse direito. "A alfabetização tem também o papel de promover a participação em atividades sociais, econômicas, políticas e culturais, além de ser um requisito básico para a educação continuada durante a vida".

Continuando a argumentação acerca da função de reparação da EJA, o Parecer explicita que, em nossa sociedade, o caráter comum da linguagem esconde quanto o acesso a esse bem é importante. Sendo assim, a ausência da leitura e da escrita pode levar a novas formas de estratificação social, além de ser um instrumento de poder dos que a dominam. Nesse ponto, o Parecer aponta o analfabetismo como uma das causas das diferenças sociais existentes na sociedade burguesa, possibilitando entender, também, que o domínio da leitura e escrita pode contribuir para o fim da estratificação social. Expõe que o acesso ao conhecimento sempre teve um papel importante na divisão social, processo que se acentua, hoje, com as exigências intelectuais básicas requeridas pela chamada sociedade do conhecimento (BRASIL, 2000).

Para reforçar a idéia de que a escola constitui-se em um meio de alterar a posição do indivíduo na sociedade, no Parecer, explicita-se que a aquisição da leitura e escrita pode: possibilitar a existência de um espaço democrático de conhecimento e postura tendente a assinalar um projeto de sociedade menos desigual; auxiliar na eliminação das discriminações e, nessa medida, abrir espaço para outras modalidades mais amplas de liberdade; contribuir para universalização do ensino fundamental e médio, levando ao acesso aos conhecimentos científicos, que permitem a superação de poderes assentados no medo e na ignorância; constituir-se em uma via de reconhecimento de si, da auto-estima e do outro como igual; abrir caminho para que os cidadãos possam apropriar-se de conhecimentos avançados, contribuindo para a consolidação de pessoas mais solidárias e de países mais autônomos e democráticos; permitir a participação no mercado de trabalho, no qual a exigência sobre o ensino fundamental impõe-se como realidade (BRASIL, 2000).

A alfabetização, a aquisição da leitura e escrita, portanto, constituir-se-iam em meios de inclusão social e a reparação de uma dívida histórica para com a classe trabalhadora. O Parecer considera que o Estado tem papel importante na promoção de políticas públicas que atuem no campo das desigualdades sociais. A função reparadora, segundo o documento, tornar-se-ia uma oportunidade para a inclusão dos jovens e dos adultos na escola e uma opção viável para um grupo com especificidades socioculturais para o qual se espera uma efetiva atuação das políticas sociais implementadas pelo Estado (BRASIL, 2000).

Argumenta-se no Parecer que as várias instituições da sociedade civil devem ser chamadas à reparação dessa dívida, em regime de colaboração com os poderes públicos. Percebemos a estreita vinculação entre as diretrizes expostas no Parecer e as orientações das agências internacionais, que apontam para a necessidade de participação da sociedade civil na efetivação das políticas sociais e a focalização das ações do Estado na educação básica.

A função reparadora da EJA é apresentada no Parecer (BRASIL, 2000) como propiciadora do ingresso no mercado de trabalho. Argumenta-se que a EJA constitui-se em 
uma oportunidade de atender à atual exigência das competências requeridas pela vida cidadã e do mercado de trabalho. Enfatiza-se que a existência do desemprego, do subemprego, do desemprego estrutural e do trabalho informal, decorrente de mudanças nos atuais processos de produção, pode produzir uma instabilidade para os indivíduos, sendo muito mais atingidos aqueles que são desprovidos da leitura e da escrita.

A nosso ver, a idéia central da função reparadora atribuída à EJA é a inclusão. Busca-se, por meio da EJA, a inclusão no sistema educacional daqueles que estão fora da escola. O raciocínio é que, como conseqüência da inclusão escolar, haveria a inclusão na vida cidadã e, com ela, o acesso ao mercado de trabalho. Podemos inferir que, de acordo com o Parecer, torna-se imperioso, para tornar-se cidadão, estar inserido no mundo produtivo. A inserção ou inclusão, nesse caso, depende do acesso aos conhecimentos produzidos pela chamada sociedade do conhecimento.

O documento da Câmara de Educação Básica reconhece que os problemas do analfabetismo e da exclusão social e educacional são de ordem histórico-social, mas transfere para a escola e para o indivíduo a busca pela superação desse estado. Nesse ponto, inserimos a questão da individualização do fracasso, desenvolvida por Netto (2001). Para esse autor, nas condições da atual fase do desenvolvimento capitalista, ou seja, um prolongamento direto da sua fase monopolista, o caráter público com que as questões sociais são tratadas absorve o substrato individualista da tradição liberal que considera que o destino da pessoa é função do indivíduo como tal, como conseqüência, são creditados ao sujeito individual tanto o êxito como o fracasso social. O Estado burguês, ao mesmo tempo em que intervém nos problemas sociais, debita a continuidade das sequielas sociais aos indivíduos por elas afetados, na concepção de políticas sociais (NETTO, 2001, p. 36).

Montaño (2003) aponta que as políticas sociais estatais são alteradas significativamente e, aos poucos, retiradas da órbita do Estado, em um processo de privatização por meio da sua transferência para o mercado ou a sociedade civil, em decorrência da nova estratégia hegemônica do grande capital (o neoliberalismo), da reestruturação produtiva, da reforma do Estado e da globalização da produção. Como decorrência desse processo de privatização, a própria sociedade e as famílias passam a ser os responsáveis pelas políticas de bem-estar, como educação e saúde.

O que fica para o Estado neoliberal, em termos de políticas sociais, é realizado com ações focalizadas em determinados serviços oferecidos a grupos específicos da sociedade. Sobre esse assunto, Montaño (2003, p. 195) acrescenta que "[...] os 'serviços estatais para pobres` são, na verdade, 'pobres serviços estatais"”. Os indivíduos com “[...] condições de contratá-los na órbita privada terão serviços de boa qualidade; quem não puder fazê-lo e, portanto, tiver que recorrer à prestação de serviços estatais, receberá um tratamento de má qualidade, despersonalizado". Enfatiza o autor que “[...] essa precarização e diminuição dos serviços estatais ocorre justamente num contexto de crise em que se desencadeia um aumento real das necessidades, carências e demandas sociais".

Ainda sobre o papel do Estado em relação ao social, Silva Júnior (2002) explicita que, no processo de mundialização do capital, o Estado torna-se "muito forte e pouco interventor no social", porque o econômico o configura, tornando-o um Estado gestor, que se mostra democrático quando, nas questões sociais, transfere para a sociedade civil os direitos sociais e sua concretização. E acrescenta: "[...] a cidadania que deriva daí é uma cidadania produtiva", ou seja, vinculada ao processo de trabalho e a serviço dos interesses do capital. O Estado a serviço do capital financeiro tem sua ação na esfera pública restringida, mas continua forte como um estado gestor. Sua atuação na esfera privada, contudo, expande-se por meio de nova regulamentação, pela qual "[...] impulsiona, segundo a ideologia liberal, um movimento de transferência de responsabilidades de sua 
alçada para a sociedade civil, ainda que as fiscalize, avalie e financie, conforme as políticas por ele produzidas e influenciadas pelas agências multilaterais". O poder de regulação, “[...] sob a forma do 'político', é agora o poder econômico macrogerido pelo capital financeiro, com graves conseqüências para a cidadania e para a educação" (SILVA JÚNIOR, 2002, p. 33).

A idéia da inclusão deve ser entendida no contexto da exclusão, termo que, desde o último quartel do século XX, tem ocupado espaço na literatura social, sobretudo no tocante às políticas públicas sociais. Oliveira (2004) explica que esse é um conceito de uso corrente nas ciências sociais, utilizado sem grandes preocupações com sua definição. Esse autor aponta ainda que sua utilização tem ampla aceitação e abarca um conjunto cada vez maior de grupos tais como as minorias étnicas, os desempregados, os desempregados de longa duração, os sem moradias, entre outros. Ressalta que sua utilização aponta para o esboço de um "[...] movimento que visa alçar a exclusão à categoria central de um novo modelo de interpretação social" (OLIVEIRA, 2004, p. 17).

A idéia de que vivenciamos uma sociedade marcada pela divisão entre ao incluídos e os excluídos forja o consenso de que as diferenças não têm a ver com a relação social entre classes. As políticas públicas de corte social são instrumentos de tratamento das desigualdades sociais estruturais, são mecanismos utilizados pelo Estado para regular as relações sociais e controlar a questão social. Por questão social, entendemos o conjunto de problemas sociais, econômicos e políticos engendrados pela sociedade capitalista e que está, intimamente, vinculada à conflituosa relação capital-trabalho. Permanece nos limites da ação compensatória, que mantém as desigualdades e a exclusão sociais e que não contribui no sentido de as classes subalternas serem sujeitos de sua história individual e coletiva. Abandona-se a explicitação da produção social da exclusão na desigual e excludente sociedade capitalista.

Diante da argumentação apontada pelo Parecer, quem seriam os incluídos? Os incluídos seriam aqueles que têm acesso aos bens materiais e culturais produzidos pela sociedade e disponíveis no mercado. Assim, os que não têm emprego, não estão inseridos no mundo produtivo, seriam os excluídos da sociedade. Percebemos, aqui, um contrasenso: a inclusão seria dada via escola, enquanto a exclusão completa-se via mercado. Revela-se que a inclusão escolar é a única possível no capitalismo, já que a cidadania capitalista só se completa com a participação no mundo produtivo e no mercado. Trata-se de aspecto que Ramos (2003, p. 22) aponta como paradoxal, porque os processos da educação para a cidadania e para o trabalho se confundem "[...] justamente no momento em que o mercado de trabalho reserva espaço para cada vez menos pessoas".

Refletir sobre a idéia da exclusão via mercado e inclusão via escola leva-nos a pensar sobre a materialidade na qual estão assentadas, atualmente, as noções de inclusão e exclusão. Devemos considerar que as mesmas relações nas quais se produz a riqueza, se produz a miséria, sendo, portanto, a miséria e a exclusão "[...] resultado continuado e crescente do desdobramento do modo de produção capitalista” (DEL PINO, 2001, p. 69). Marx (1998) explicou que a condição essencial para a existência e o domínio da classe burguesa é a acumulação de riqueza em mãos de particulares. Enquanto não houver a superação do modo de produção fundamentado na divisão social em classes com interesses antagônicos, na qual a produção é cada vez mais socializada, mas a apropriação da riqueza social é privada, não há como superar a desigualdade social fundamental e reparar a dívida social, apontada no Parecer, a não ser parcialmente, exatamente porque são de ordem histórico-social. Quanto mais se produz a riqueza em um pólo, mais a contrapartida é a miséria no outro, quadro agravado com a magnitude dos processos de concentração e centralização do capital na fase do capitalismo mundializado. 
Sendo assim, a idéia da chamada inclusão social via escola baseia-se em um reducionismo, não se sustenta empiricamente, uma vez que a escolarização na atual fase do desenvolvimento capitalista tem sido utilizada para justificar a seletividade no mercado do trabalho (DEL PINO, 2001), já que não há lugar para todos. A idéia que o Parecer CEB 11/2000 apresenta é que a inclusão na sociedade, ou seja, no mercado, só pode ser alcançada via investimento pessoal, adquirindo características individuais apreciadas pelo capital, como a capacidade "[...] para enfrentar o emprego, o desemprego, e o autoemprego [...]" (PAIVA, 2001, p. 56).

Depreende-se que o discurso atual sobre a inclusão e a exclusão social, expressão da função reparadora da EJA, tem transferido para o indivíduo a responsabilidade por adquirir a capacidade de incluir-se, ou não, nessa sociedade. Isso contribui para encobrir a realidade social que produz a exclusão, além de impedir uma discussão sobre as possibilidades reais de sua superação.

A estreita vinculação entre a EJA e o mundo do trabalho, ao definir as novas competências exigidas pelas transformações da base econômica do mundo contemporâneo, está expressa no Parecer CEB 11/2000 na afirmativa de que, cada vez mais, requer-se o acesso a saberes diversificados em decorrência das competências novas que são "[...] exigidas pelas transformações da base econômica do mundo contemporâneo, o usufruto de direitos próprios da cidadania, a importância de novos critérios de distinção e prestígio, a presença dos meios de comunicação assentados na microeletrônica”. Destarte, a igualdade e a desigualdade permanecem mantendo relação imediata com o trabalho. Tanto para o trabalho quanto para a multiformidade de inserções sociopolítico-culturais, “[...] aqueles que se virem privados do saber básico, dos conhecimentos aplicados e das atualizações requeridas podem se ver excluídos das antigas e novas oportunidades do mercado de trabalho e vulneráveis a novas formas de desigualdades" (BRASIL, 2000, p. 37-38).

Rummert (2000, p. 61) destaca ser hoje idéia comum que o acesso ao mercado material social e simbólico - torna-se uma questão de mérito pessoal. E acrescenta: “[...] recompõe-se, assim, o mito da permanente vitória do bem sobre o mal, do forte e capaz sobre o medíocre, sobretudo, reforça-se uma leitura maniqueísta e positivista da realidade". Adverte, também, que, nesse processo, naturalizam-se a riqueza e a miséria, que expressam a maior ou menor capacidade de cada um obter sucesso. Soma-se isso a idéia de que a cidadania constitui-se em um prêmio para os vencedores, tornando-se ela mesma uma cidadania voltada aos interesses do mercado de trabalho.

Frigotto (2004, p. 7), ao discutir a questão da cidadania e a formação profissional como desafios para o fim do século XX, chama a atenção para o processo que ele denomina de exclusão sem culpa. Explicita o referido autor que a desigualdade existente na sociedade capitalista não se explica pelas relações sociais de classe, de violência e de exclusão, intrínsecas ao modo de produção capitalista, mas pela vontade e comportamento do indivíduo singular. O livre-mercado constitui-se como o "[...] lócus onde vontades livres, e supostamente iguais por natureza, oferecem os seus serviços à sociedade ao mesmo tempo satisfazendo suas necessidades". O mesmo autor alerta para o fato de que a "[...] classe trabalhadora que se constitui na gênese da sociedade capitalista é preliminarmente constituída por excluídos dos meios e instrumentos de produção". As situações que se apresentam como escolhas igualitárias, na realidade, constituem-se na legitimação da desigualdade, e a conseqüência disso, como expõe Frigotto (2004, p. 7), é que, alicerçado neste ideário, "[...] a sociedade capitalista estatui a cidadania de direitos sociais, econômicos, culturais, lúdicos, educacionais para poucos, e uma cidadania de segunda categoria para as maiorias". Dessa forma, justifica pela má escolha individual e dá legitimidade à dualidade de processos educativos e formativos, reservando à classe que 
vive da venda da força de trabalho "[...] o ensino técnico-profissional marcado pelo adestramente, treinamento, requalificação, formação de competências, no limite numa perspectiva da polivalência, regulada pelas necessidades da produção sob a égide do mercado capitalista".

Ressaltamos que, no tocante aos discursos das agências internacionais ou dos próprios empresários nacionais, a educação é vista como condição essencial de superação dos problemas da sociedade e do indivíduo. Se a exclusão do mercado de trabalho é fruto do despreparo do indivíduo, a solução apresenta-se via retomada dos estudos para jovens e adultos que não concluíram o ensino fundamental e médio em idade considerada apropriada. A educação que se apresenta como reparadora, destinada aos jovens e aos adultos analfabetos ou pouco escolarizados, deve, segundo a ótica empresarial: ser ofertada com caráter especial; voltada para o atendimento emergencial da demanda reprimida; contar com recursos metodológicos, materiais e financeiros próprios além da participação da sociedade civil em sua concretização. Essas prerrogativas, primeiramente apontadas pelos documentos produzidos pelas agências internacionais, encontram-se materializadas na legislação educacional brasileira produzida no final dos anos 1990.

Em termos de discurso oficial, a EJA tem recebido destaque enquanto instrumento de reparação da dívida social, que é a educação para os jovens e para os adultos analfabetos ou pouco escolarizados. Devemos considerar que, na prática, a adequação do Brasil às exigências internacionais do capitalismo mundializado torna a educação um serviço social que deve atender às necessidades básicas da população. O básico em termos educacionais passou a ser o ensino fundamental dos sete aos quatorze anos, fazendo com que os investimentos na EJA sigam as estratégias de focalização e descentralização, premissas das reformas educacionais da última década do século XX. Nos anos 1990, a EJA reparadora efetivou-se sobretudo por meio de cursos aligeirados ou exames de suplência conformados com a questão da qualidade e eficiência, que passaram a ser entendidas como a apresentação de dados estatísticos com altos índices de conclusão.

A EJA reparadora leva-nos a refletir sobre o fracasso escolar, os altos índices de analfabetismo no Brasil, a reprovação e a evasão, entre outros problemas. No âmbito deste texto, interessa-nos refletir sobre a motivação que leva os jovens e os adultos analfabetos ou pouco escolarizados a buscar a conclusão dos estudos nas etapas fundamental e média.

No Brasil, no início do século XX, as transformações ocorridas com o processo de industrialização e urbanização foram acompanhadas por um "aumento de ocupações não manuais e uma maior demanda da população pela educação formal". Na década de 1950, o nível primário de escolarização garantia o acesso ao mercado de trabalho em muitos postos. Nas décadas seguintes e particularmente nos anos 1990, a tendência a se exigir maior grau de instrução para a inserção no mercado de trabalho se acentuou, (ZAGO, 2000, p. 23). Esse fenômeno é atribuído por Saes (2004) à sobrequalificação produzida pela pressão da classe média pelo ensino superior, e não à intenção dos empresários.

Podemos afirmar, segundo conclusões da pesquisa empírica realizada por Zago (2000, p. 24) com jovens oriundos das camadas médias e populares, que a volta à escola se apresenta como requisito básico para responder às exigências do mercado de trabalho e, sobretudo, como "[...] possibilidade de romper com as condições de pobreza familiar". A autora citada evidencia que as famílias das camadas populares valorizam a instrução escolar ancoradas em dois aspectos: no primeiro, vê a escola como propiciadora dos domínios dos saberes fundamentais e integração ao mercado de trabalho e, no segundo, a escola se apresenta como espaço de socialização e proteção dos filhos do contato com a rua e as drogas. 
Não obstante, a mesma pesquisa revela que, embora haja o reconhecimento da família e do jovem/adulto da valorização pró-escola, há uma clara percepção dos "[...] limites impostos pelas condições materiais objetivas [...]" que obriga a uma opção pelo trabalho em detrimento da vida escolar (ZAGO, 2000, p. 30). Assim, premidos pelas exigências do mercado de trabalho, "[...] os jovens que não freqüentaram a escola na idade prevista tentam ou fazem projetos para retomar os estudos, geralmente através do ensino regular noturno, ou de fórmulas mais rápidas que podem ser viabilizadas pelos cursos supletivos". Regulamente, é dentro destas modalidades que o futuro escolar é projetado nas camadas populares e visa a conciliação entre estudo e trabalho (ZAGO, 2000, p. 27).

Tomados pela idéia de que a retomada dos estudos poderá lhes garantir um lugar no disputado mercado de trabalho formal, muitos jovens, ainda de acordo com a pesquisa de Zago (2000, p. 32), voltam à escola com uma preocupação maior em relação à obtenção do certificado do que com o saber escolar em si mesmo. A posição assumida por aqueles que não conseguiram um certificado escolar é a de transferir para si mesmos a responsabilidade pelo fracasso escolar, considerando-se os "[...] principais responsáveis pelo baixo nível escolar e, quanto aos resultados obtidos, os atribuem principalmente às características individuais como incompetência e desinteresse".

Sobre a pesquisa de Zago (2000), Saes (2004) complementa que, para os trabalhadores manuais, a instrução rudimentar (ler, escrever e contar) torna-se importante para o acesso ao mercado de trabalho. O cálculo da renda familiar perdida com a manutenção dos filhos na escola faz com que muitos pais trabalhadores relativizem a importância da conclusão do ensino fundamental, assumindo uma posição fatalista ao verem seus filhos de doze, treze e quatorze anos ingressarem no mercado de trabalho informal ou eventual, abandonando a escola. Ainda para esse autor, as classes populares sabem que somente uma parcela muito pequena dos trabalhadores manuais com formação profissional ampla é absorvida pelo marcado de trabalho. Explicita que, na prática, há desconfiança por parte do proletariado ao "[...] apelo tecnocrático para que 'todos' obtenham uma "formação polivalente"”. Há a percepção de que "[...] o aparelho produtivo do capitalismo pede à maioria dos trabalhadores tão-somente a capacidade adaptativa de passar rapidamente, no 'canteiro de obras', de uma tarefa limitada para outra tarefa limitada" (SAES, 2004, p. 74-75).

O Parecer CEB 11/2000, ao apresentar a EJA como reparadora de uma dívida social para com aqueles que não tiveram oportunidade de concluir seus estudos em idade apropriada, colabora com a idéia de que, por meio da escola, é possível a inserção profissional e a melhoria das condições de vida do indivíduo, que vê nas suas características pessoais a responsabilidade pelo fracasso escolar e profissional.

Percebemos, nessa premissa, um incentivo à competição, corroborando a atomização social, na medida em que a idéia que se difunde é a de que cada um deve buscar a superioridade sobre os demais por meio da luta isolada por seus interesses e necessidades (RUMMERT, 2000). Podemos relacionar essa idéia à idéia-chave de que o acréscimo marginal de instrução, treinamento e educação constitui-se em um acréscimo de capacidade de produção, noutras palavras, de capital humano, indicativo de um determinado volume de conhecimentos, habilidades e atitudes adquiridos, capazes de potencializar a produção (FRIGOTTO, 1996). Esse é o sentido do termo empregabilidade que revigora a idéia de que investir no capital humano torna-se rentável, tanto para as nações quanto para os indivíduos.

A idéia é que a pretendida inclusão, que o Parecer CEB 11/2000 aponta, constituise, na verdade, em uma inclusão subordinada. Garcia (2004) explica que um dos matizes do conceito de inclusão está envolto por um conjunto de expressões que sugerem uma nuance humanitária. Conforme explica a autora, sob “[...] este signo encontram-se justiça 
social, coesão, solidariedade, pertencimento, que, ao serem considerados politicamente corretos, legitimam os discursos em questão" (GARCIA, 2004, p. 10).

Existe uma variada e complexa teia na qual estão entrelaçados os elementos e os processos que se fazem presentes na constituição do nosso objeto de investigação. As políticas públicas, incluindo as destinadas à EJA, são resultantes do embate entre as orientações externas e os interesses internos decorrentes do processo de acumulação capitalista, dos conflitos de classe e dos acordos feitos nas esferas de poder que perpassam as instituições do Estado e da sociedade como um todo. Exatamente porque são planejadas e implementadas em relações sociais que plasmam as assimetrias, por ela perpassam a exclusão e as desigualdades que se configuram na sociedade capitalista.

\section{REFERÊNCIAS}

ANTUNES, Ricardo. Os sentidos do trabalho. Ensaio sobre a afirmação e a negação do trabalho. São Paulo: Boitempo, 1999.

Adeus ao trabalho? Ensaio sobre as metamorfoses e a centralidade do mundo do trabalho. 7. ed. ver. ampl. São Paulo: Cortez, 2000.

BRASIL. Lei de Diretrizes e Bases da Educação (Lei 9.394/96). Rio de Janeiro: DP\&A, 2003.

.Lei $n^{\circ} 9424$ de 24 de dezembro de 1996. Dispõe sobre o Fundo de Manutenção e Desenvolvimento do Ensino Fundamental e de Valorização do Magistério.

Constituição da República Federativa do Brasil: promulgada em 05 de outubro de 1988. São Paulo: Saraiva, 2002. (Coleção Saraiva de Legislação).

Ministério da Educação. V Conferência Internacional sobre Educação de Adultos. Brasília: MEC/SEF, 1998.

Conselho Nacional de Educação. Câmara de Educação Básica. Carlos Roberto Jamil Cury (relator). Parecer CEB11/2000 - Diretrizes curriculares nacionais para a educação de jovens e adultos.

Conselho Nacional de Educação. Câmara de Educação Básica. Resolução CEB1/2000 - Diretrizes curriculares nacionais para a educação de jovens e adultos.

DEL PINO, Mauro. Política educacional, emprego e exclusão social. In: GENTILI, Pablo; FRIGOTTO, Gaudêncio. A cidadania negada: políticas de exclusão na educação e no trabalho. São Paulo: Cortez, 2001. p. 65-88.

DI PIERRO; GRACIANO, Mariângela. A educação de jovens e adultos no Brasil. Informe apresentado à Oficina Regional da Unesco para a América Latina y Caribe. São Paulo: Ação Educativa, 2003.

FRIGOTTO, Gaudêncio. Cidadania e formação técnico profissional. Desafios neste fim de século. A página da educação. Disponível em: <http//www.apagina.pt/arquivo/artigo $>$. Acesso em: 16 maio 2004.

Educação e a crise do capitalismo real. 2. ed., São Paulo: Cortez, 1996.

GARCIA, Rosalba Maria Cardoso. Discursos políticos sobre inclusão: questões para políticas públicas de educação especial no Brasil.In: REUNIÃ̃ ANUAL DA

Revista HISTEDBR On-line, Campinas, n. Especial, p 225-237, mai.2009 - ISSN: 1676-2584 
ASSOCIAÇÃO NACIONAL DE PESQUISA E PÓS GRADUAÇÃO EM EDUCAÇÃO, Anais 2004 da $27^{\text {a }}$ Reunião Anual da ANPEd. Caxambu, MG, 2004.CD Rom. p. 1-14

MARX, Karl. Manifesto do partido comunista. Prólogo de José Paulo Netto. São Paulo: Cortez, 1998.

MONTAÑO, Carlos. Terceiro setor e questão social: crítica ao padrão emergente de intervenção social. São Paulo: Cortez, 2003.

NETTO, José Paulo. Capitalismo monopolista e serviço social. 3. ed. São Paulo: Cortez, 2001 .

NETTO, José Paulo; BRAZ, Marcelo. Economia política: uma introdução crítica. São Paulo: Cortez, 2006.

OLIVEIRA, Avelino da Rosa. Marx e a exclusão. Pelotas: Seiva, 2004.

PAIVA, Vanilda. Qualificação, crise do trabalho assalariado e exclusão social. In:

GENTILI, Pablo; FRIGOTTO, Gaudêncio. A cidadania negada: políticas de exclusão na educação e no trabalho. São Paulo: Cortez, 2001. p. 49-64.

RAMOS, Marise Nogueira. O "novo" ensino médio à luz de antigos princípios: trabalho, ciência e cultura. Boletim Técnico do Senac. Rio de Janeiro, v. 29, n. 2, p. 19-27, maio/ago. 2003.

RUMMERT, Sônia Maria. Educação e identidade dos trabalhadores: as concepções do capital e do trabalho. São Paulo: Xamã, 2000.

SAES, Décio Azevedo Marques de. Educação e socialismo. Crítica Marxista. Campinas, n. 18, p. 73-83, maio 2004.

SILVA JÚNIOR, João dos Reis. A reforma do estado e da educação no Brasil de FHC. São Paulo: Xamã, 2002.

ZAGO, Nadir. Processos de escolarização nos meios populares: as contradições da obrigatoriedade escolar. In: NOGUEIRA, Maria Alice; ROMANELLI, Geraldo; ZAGO, Nadir. Família e escola: trajetórias de escolarização em camadas médias e populares. Rio de Janeiro, Vozes, 2000. p. 17-44.

\footnotetext{
${ }^{1}$ Esse Programa é parte integrante das propostas de Reforma Agrária e é desvinculado do MEC. Suas ações compreendem a Educação Básica compensatória e o ensino superior.

${ }^{2}$ O Planfor foi substituído pelo Plano Nacional de Qualificação - PNQ por meio da Resolução n ${ }^{\circ} 333$ de 10 de julho de 2003, sua implantação ocorreu a partir de 2004.
}

Artigo recebido em: 13/12/2008

Aprovado para publicação em: 15/01/2009 